Alma Mater Studiorum - Università di Bologna DEPARTMENT OF ECONOMICS

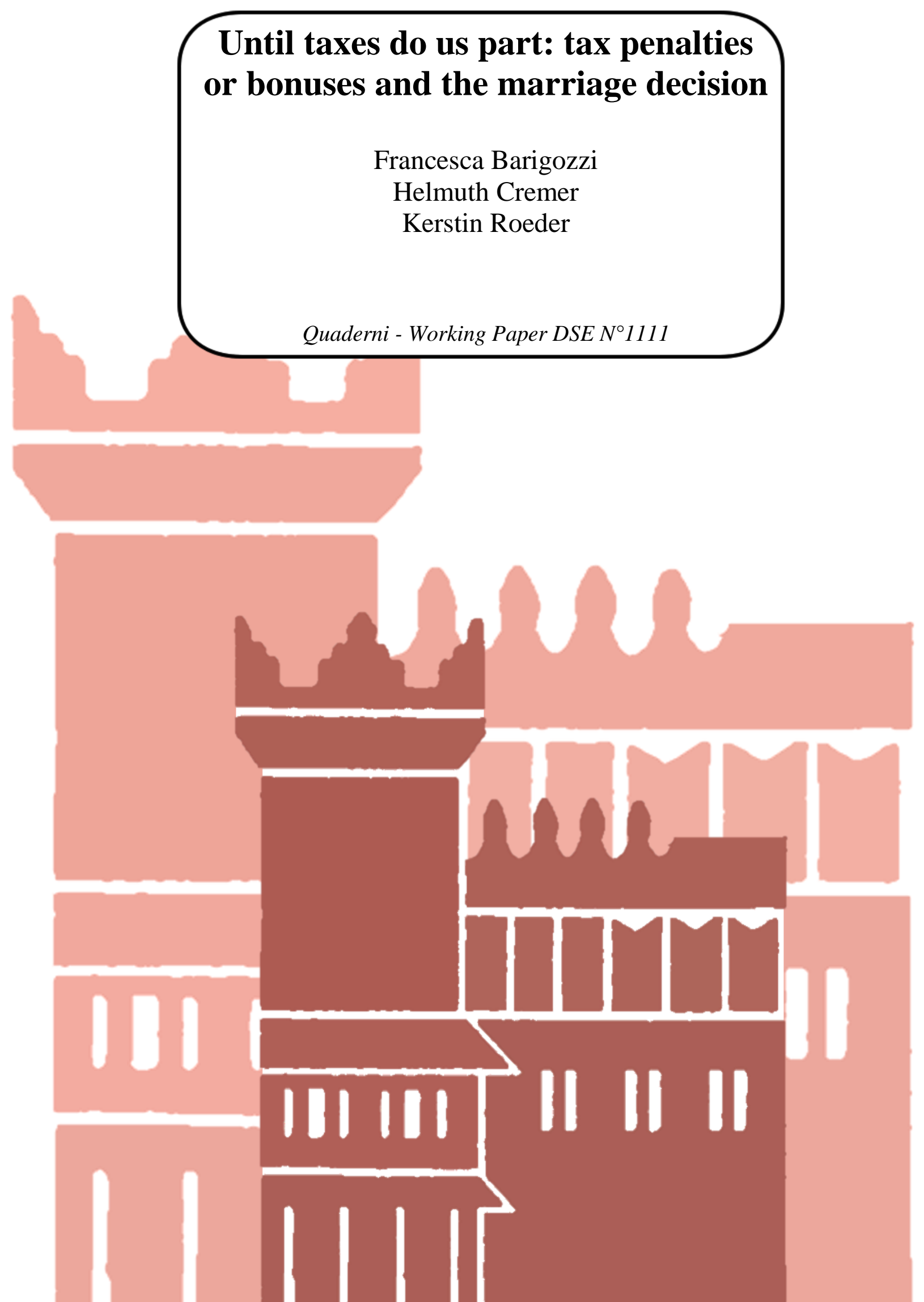




\title{
Until taxes do us part: tax penalties or bonuses and the marriage decision
}

\author{
Francesca Barigozzi ${ }^{1} \quad$ Helmuth Cremer $^{2} \quad$ Kerstin Roeder $^{3}$
}

October 2017

\footnotetext{
${ }^{1}$ University of Bologna, Italy, Email: francesca.barigozzi@unibo.it.

${ }^{2}$ Toulouse School of Economics, University of Toulouse Capitole, France, Email: helmuth.cremer@tse-fr.eu.

${ }^{3}$ University of Augsburg, Germany, Email: kerstin.roeder@wiwi.uni-augsburg.de.
} 


\begin{abstract}
The tax regimes applied to couples in many countries including the US, France, and Germany imply either a marriage penalty or a marriage bonus. We study how they affect the decision to get married by considering two potential spouses who play a marriage proposal game. At the end of the game they may get married, live together without formal marriage, or split up. In this signaling game, proposing (or getting married) is costly but can indicate strong love. The striking property we obtain is that a marriage bonus may actually reduce the probability that a couple gets married. If the bonus is sufficiently large, the signaling mechanism breaks down, and only a pooling equilibrium in which fewer couples get married remains. Similarly, a marriage penalty may increase the marriage probability. Specifically, the penalty may lead to a separating equilibrium with efficiency enhancing information transmission, which was otherwise not possible. Our results also imply that marriage decisions in the laissez-faire are not necessarily privately optimal. In some cases a bonus or a penalty may effectively make the marriage decision more efficient; it may increase the number of efficient marriages that otherwise may not be concluded.
\end{abstract}

JEL classification: J12, D82, H31

Keywords: marriage penalty, marriage bonus, proposal game, signaling 
My most brilliant achievement was my ability to be able to persuade my wife to marry me.

Winston Churchill

\section{Introduction}

Except when income taxes are purely individual based, the tax regimes applied to couples typically imply either a marriage penalty or a marriage bonus. A marriage penalty involves higher taxes for married couples than for two otherwise identical single individuals with exactly the same income; a bonus implies lower taxes for married couples. A marriage penalty applies, for instance, in the US; see Alm et al. (1999). In France or Germany, on the other hand, there is a marriage bonus due to income splitting. ${ }^{1}$ While there appears to be a trend towards more individualized tax systems, very few systems are effectively completely neutral with respect to the marital status; see OECD $(2005 ; 2017)$. Table I2.3 in OECD (2015) shows that a majority of countries nominally have an individual based tax system. Table I2.1, on the other hand, shows that this is very often just a matter of legal terminology. Even when the tax unit is referred to as individual based, there is in most instances some correction reflecting the marital status.

To sum up, in reality in most tax systems a couple's tax liability depends on its marital status. Many systems are less extreme than the French or the German ones, but they are nevertheless not completely neutral. Consequently, they potentially affect a couple's decision to get married in the first place. Empirical papers suggest that the bonus or penalty have little impact on the marriage decision, which is rather surprising since the bonus can be rather sizeable like in France or Germany; see Leturcq (2012) for an overview of this literature. ${ }^{2}$

\footnotetext{
${ }^{1}$ In France and Germany each spouse's taxable income is defined as half of total family income. The couple's total tax liability is then twice the tax calculated for each spouse. Because of the concavity of the tax function this reduces the couples' tax liability unless both spouses have identical incomes or, at least, are in the same tax bracket.

${ }^{2}$ Leturcq (2012) concentrates on civil unions rather than on marriage. However, in the introduction
} 
The existing theoretical literature on couple taxation mostly ignores how taxation affects the decision to get married. ${ }^{3}$ As pointed out by Kaplow (2008, page 342) “... a scheme that is ideal on distributive grounds is likely to influence marriage decisions." In other words, it is unlikely that a purely individualistic tax (which would be neutral with regard to the marriage decision) is optimal." ${ }^{4}$ But it is not clear whether this optimal joint taxation fosters or discourages marriages. In principle, this can go both ways: with a German or French style income splitting it "pays"to get married (as long as spouses have different incomes), while the US system goes in the opposite direction. To the best of our knowledge, there is no general result in tax theory concerning the desirability of a marriage bonus or penalty. Either way, assuming that the marriage decision would be otherwise privately optimal, the effect a tax system has on this decision represents an extra distortion, which should be accounted for when designing the optimal policy.

In this paper we study the impact of a marriage bonus or penalty on the decision to get married. From a positive perspective, this provides an analysis of how real world tax systems affect the decision to get married. But first and foremost our analysis is meant to provide guidance to future research on the optimal taxation of couples. As Kaplow puts it, the impact of a tax system on the decision to get married represents an additional distortion to be accounted for in couple taxation models. We show that this distortion may be far more complex than one could expect. Specifically, we show that a marriage bonus may not increase the number of marriages while a penalty may induce additional marriages. Furthermore, Kaplow's implicit assumption that in the

she extensively discusses the literature which has looked at the impact of the tax system on marriage, mainly in the US, but also in France.

${ }^{3}$ See, for instance, Boskin and Sheshinski, (1983); Apps and Rees (1999); Cremer, Lozachmeur and Pestieau (2012), or, more recently, Cremer et al. (2016). Chade and Ventura (2002) do study tax design with endogenous marriages, but they focus on tax reform rather than on optimal taxation. They consider a marriage-market model with search frictions and heterogeneous agents. They show that reforms leading to more neutral systems (which for the US means reducing the marriage penalty) may increase or decrease the number of couples who get married. In a follow up paper Chade and Ventura (2005) consider a simplified version of their model for which they can study tax optimization albeit with very restricted instruments. They show that it is optimal to give a married couple a preferential tax treatment for this allows to correct an inefficiency in the matching process.

${ }^{4}$ For a given family structure, the optimal tax schedule is determined by a number of possibly conflicting effects. These include issues of redistribution between and within couples, labor supply elasticities (Ramsey considerations), efficiency of household production, etc.; see Apps and Rees (2009, Ch 6); or Kaplow (2008, Ch 12) for detailed overviews. 
laissez-faire the marriage decision is privately optimal may not be true. In other words, the "distortion" of the individual marriage decision implied by the tax system may effectively be welfare improving.

We consider a model where two potential spouses play a marriage proposal game at the end of which they may get married, live together without formal marriage, or split up. This is a signaling game where proposing, or more generally getting married, is costly but can indicate strong love (a high quality match). The striking property we obtain is that a marriage bonus may actually reduce the probability that a couple gets married. If it is sufficiently large, the signaling mechanism breaks down, and there is only a pooling equilibrium in which fewer potential couples get married. Similarly, a marriage penalty may increase the marriage probability. Specifically, the penalty may lead to a separating equilibrium with efficiency enhancing information transmission, which was otherwise not possible.

This setting is rather specific, but the results suggest that integrating the decision to get married into a family taxation model may have to account for a priori surprising behavioral responses. A marriage subsidy may not enhance marriages while a penalty does not necessarily discourage marriages. Furthermore, marriage decisions in the laissez-faire are not necessarily efficient. This is quite in line with the empirical results which show little impact at the aggregate level. Since the effect can go both ways (depending on the couple's characteristics) on aggregate these will cancel out (in part). Another interesting lesson is that the impact of the tax system on the marriage decision does not necessarily represent a "distortion", that is a welfare cost. In some cases a bonus or a penalty may effectively make the marriage decision more efficient; it may increase the number of efficient marriages that otherwise may not be concluded.

Signaling in the marriage market has been analyzed as a mean to overcome asymmetric information and allow profitable matching. However, earlier studies emphasize the role of status goods and conspicuous consumption as signals of income, which represents a crucial but unobservable characteristic evaluated by potential partners (see De Fraja 2009, Bronsert et al. 2016, and references within)..$^{5}$ Our signaling model has a

\footnotetext{
${ }^{5}$ De Fraja (2009) explicitly links utility maximization to the biological problem of fitness maximiza-
} 
different focus. First potential partner signal their feelings and not other material characteristics. Second, in line with Bénabou and Tirole (2006), it examines how pecuniary incentives might interact with individuals' intrinsic motivation by diluting the signaling value of (virtuous) behavior.

\section{The Model}

\subsection{The marriage proposal game}

Sam $(S)$ and Robin $(R)$, any gender, are two potential partners who interact strategically. ${ }^{6}$ Sam's unobservable feelings for Robin are represented by the parameter $\theta_{S} \in$ $\left\{\theta_{L}, \theta_{H}\right\}$ with $\theta_{H}>\theta_{L}>0$. With probability $\lambda$ Sam's love is strong $\left(\theta_{S}=\theta_{H}\right)$, with probability $1-\lambda$ it is weak $\left(\theta_{S}=\theta_{L}\right)$. This parameter determines the partners' utility if they remain together.

Sam chooses the action $a_{S} \in\{0, c, m\}$. Specifically, if $a_{S}=m$ Sam asks Robin for marriage; if $a_{S}=c$ (cohabitation or civil union) Sam asks Robin to live together without formal marriage. Finally, when $a_{S}=0$ Sam breaks the relationship. In this case the game ends and both partners receive their reservation utilities $\underline{U}_{S}$ and $\underline{U}_{R}$, where $\underline{U}_{S}, \underline{U}_{R}>0$ represent possible future matches with other potential partners. To ensure that Robin's incomplete information about Sam's feelings is relevant for the outcome, we assume throughout the paper that

$$
\begin{aligned}
E\left[\theta_{S}\right] & =\lambda \theta_{H}+(1-\lambda) \theta_{L}<\underline{U}_{R}, \\
\theta_{L} & <\underline{U}_{R}<\theta_{H} .
\end{aligned}
$$

In words, condition (1) implies that absent any information acquisition, Robin's expected value of $\theta_{S}$ is smaller than her reservation utility. Consequently, Robin prefers

$\overline{\text { tion and survival. Bronsert et al. (2016) }}$ present a model where a woman interested in the wealth of a potential husband designs a screening mechanism by assigning a probability of marriage to possible amounts of wasteful consumption. Hence, screening leads to status consumption and wasteful gift giving.

${ }^{6}$ As illustrated by the choice of the player's name our game is meant to represent the proposal game of any pair of potential partners irrespective of their gender. This gender neutrality is implicit in all our arguments even though we often refer to Sam as "he" and Robin as "she". This concession turned out to be necessary to keep avoid the tedious "he or she". Using the plural of the singular "they" would have made many statements ambiguous. 
to look for a new partner when the initial uncertainty about Sam's love persists. Condition (2), on the other hand, implies that Robin wants to accept Sam's proposal if she knows for sure that his love is strong $\left(\theta_{S}=\theta_{H}\right)$, while she would refuse the proposal if she knew that his feelings are weak $\left(\theta_{S}=\theta_{L}\right)$.

Sam's action implies a cost $\varphi_{S}\left(a_{S}\right)$. We assume that $\varphi_{S}(0)=\varphi_{S}(c)=0$, while $\varphi_{S}(m)=\Phi-\theta_{S}$, where $\Phi>\theta_{H}>\theta_{L}$. The function $\varphi_{S}(\cdot)$ captures the costs associated with the marriage proposal. In particular, the marriage proposal entails time consuming and costly activities such as planning the perfect arrangement for the proposal and buying the engagement ring. Furthermore, with some probability the couple may split up through a costly divorce. ${ }^{7}$

This cost decreases with $\theta_{S}$, the intensity of Sam's feelings, for example because Sam enjoys, to a certain extent, planning for the proposal and spending money for the engagement ring and this is especially true when he is deeply in love with Robin.

After observing Sam's action, Robin chooses $a_{R} \in\{y, n\}$, meaning that Robin can either accept Sam's proposal $\left(a_{R}=y\right)$ or break the relationship $\left(a_{R}=n\right)$.

The two partners' utilities are given by

$$
\begin{aligned}
& U_{R}=(1-I) \underline{U}_{R}+I \theta_{S}, \\
& U_{S}=(1-I) \underline{U}_{S}+I\left[k \theta_{S}-\varphi_{S}\left(a_{S}\right)\right],
\end{aligned}
$$

where $I$ is an indicator function which takes the value $I=1$ if $a_{S} \in\{c, m\}$ along with $a_{R}=y$ (Sam and Robin stay together) and the value $I=0$ otherwise (either Sam or Robin breaks the relationship). When Robin and Sam remain together, their utilities are increasing in Sam's love. The parameter $k$ measures the extent to which Sam enjoys living with Robin. Our main results are obtained for the case where $k$ is large enough to ensure $k \theta_{H}>k \theta_{L} \geq \underline{U}_{S}$. This implies that Sam always prefers to remain with Robin if the proposal cost $\varphi_{S}\left(a_{S}\right)$ is not too large. Recall that from assumptions (1) and (2) Robin always prefers to look for a new partner when Sam's feelings are weak, or when she is uncertain about Sam's feelings, that is $\theta_{L}<E\left[\theta_{S}\right]<\underline{U}_{R}$.

\footnotetext{
${ }^{7}$ In an alternative interpretation to our model, one can think of the expected cost of divorce as a commitment device signaling a good match; see Appendix A.
} 


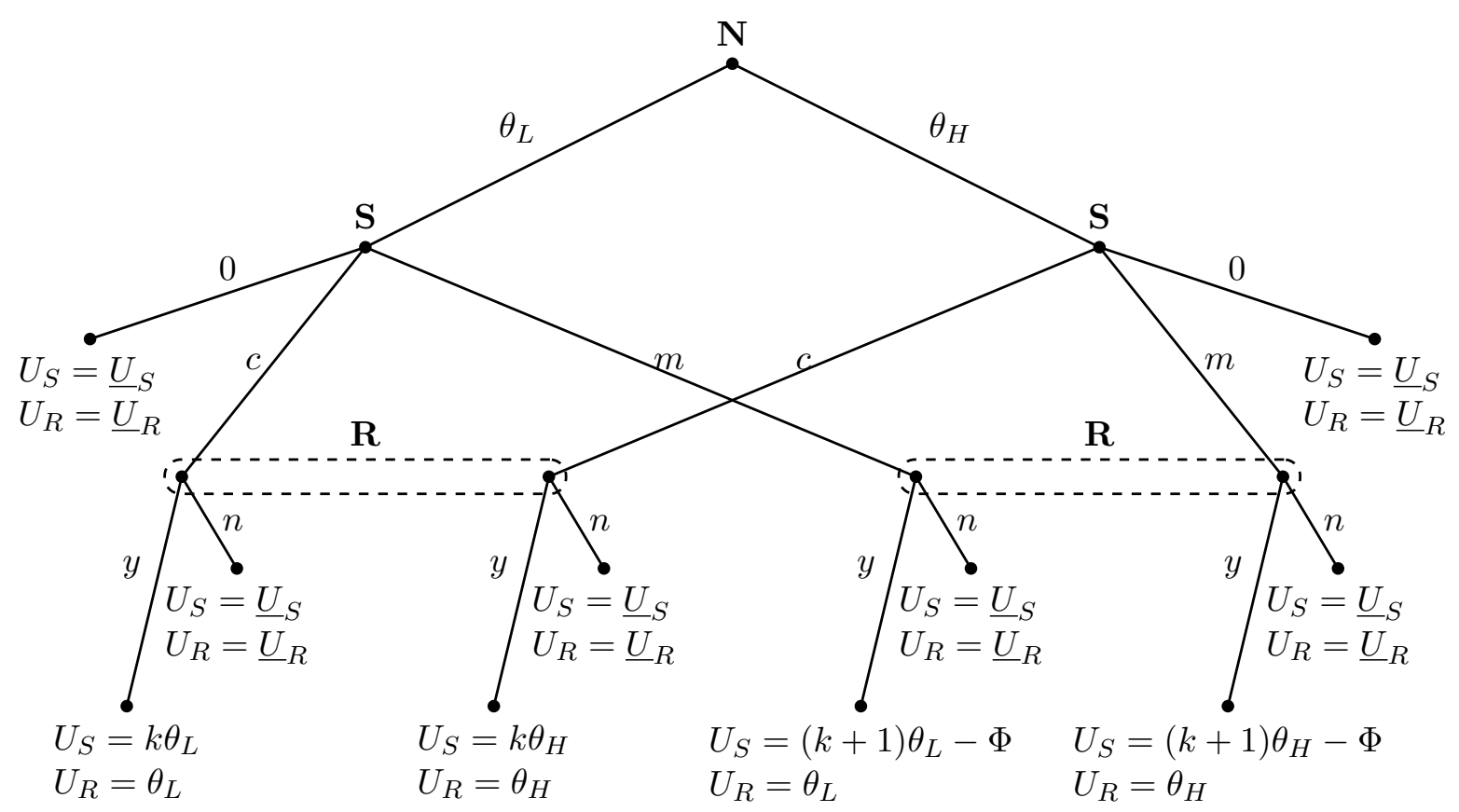

Figure 1: Game tree.

This is the most interesting case because it implies that Sam's and Robin's preferences are not perfectly aligned. This creates some incentives to lie. Specifically, when weakly in love Sam has an incentive to try to persuade Robin that he is deeply in love in order to stay together. As a consequence, a simple communication like "I am deeply in love with you" would represent mere cheap talk and would not be credible. Conversely, when deeply in love Sam may want to invest in a costly proposal to make the transmission of information about his feelings credible. ${ }^{8}$

The timing of actions is the following. First, Nature draws the type of Sam, $\theta_{S} \in\left\{\theta_{L}, \theta_{H}\right\}$, which is observable to Sam but not to Robin. Robin only knows the distribution of types. Then, Sam chooses $a_{S} \in\{0, c, m\}$. After observing Sam's action, Robin chooses $a_{R} \in\{y, n\}$. Figure 1 represents the extensive form of the game.

Given that Sam knows $\theta_{S}$, Sam's action potentially transmits some information to Robin about Sam's love. When observing Sam's action, Robin updates her beliefs using

\footnotetext{
${ }^{8}$ To show the significance of this assumption, we shall also briefly examine the case where the two partner's preferences are aligned, that is when $k \theta_{H}>\underline{U}_{S}>k \theta_{L}$; see the last paragraph of the next Section.
} 
Bayes rule. Let $\tilde{\lambda}\left(a_{S}\right)$ denote Robin's posterior belief about Sam's feelings being strong. Robin's utility when staying with Sam can then be rewritten as

$$
U_{R}=E\left[\theta_{S} \mid a_{S}\right]=\tilde{\lambda}\left(a_{S}\right) \theta_{H}+\left(1-\tilde{\lambda}\left(a_{S}\right)\right) \theta_{L}
$$

Robin will choose to remain with Sam $\left(a_{R}=y\right)$ if and only if her posterior beliefs $\tilde{\lambda}\left(a_{S}\right)$ are sufficiently large. Conversely, given $\theta_{L}<E\left[\theta_{S}\right]<\underline{U}_{R}$, Robin will break the relationship when learning that Sam's feeling are weak, or when there is no information transmission.

We will focus on Perfect Bayesian Equilibria in pure strategies.

\subsection{Marriage or cohabitation?}

Let us determine the conditions under which a separating equilibrium exists. We are interested in a separating equilibrium where Sam signals to be strongly in love $\left(\theta_{S}=\theta_{H}\right)$ by choosing the marriage proposal $\left(a_{S}=m\right)$ and where Robin, by observing the marriage proposal, infers that $\theta_{S}=\theta_{H}$ and chooses $a_{R}=y$. Conversely, when Sam's feelings are weak $\left(\theta_{S}=\theta_{L}\right)$, Sam optimally chooses $a_{S}=c$, Robin infers that $\theta_{S}=\theta_{L}$ and chooses $a_{R}=n$. Posterior beliefs are then $\tilde{\lambda}(m)=1$ and $\tilde{\lambda}(c)=0$.

This separating equilibrium exists if the two partners' incentive compatibility constraints are satisfied. In particular, when $\theta_{S}=\theta_{H}$, Sam must prefer to pay the cost of the marriage proposal and to be perceived as strongly in love instead of proposing cohabitation, and being perceived as weakly in love, in which case Robin would break the relationship. This requires

$$
(k+1) \theta_{H}-\Phi \geq \underline{U}_{S} .
$$

When instead $\theta_{S}=\theta_{L}$, Sam must prefer asking to live together, being perceived as weakly in love and remaining without a partner instead of asking for marriage and being perceived as strongly in love, that is

$$
\underline{U}_{S} \geq(k+1) \theta_{L}-\Phi \text {. }
$$

From $\left(I C_{H}\right)$ and $\left(I C_{L}\right)$ a separating equilibrium in which the players' best replies are given by $\left[\left(a_{S}\left(\theta_{H}\right)=m, a_{R}(m)=y\right) ;\left(a_{S}\left(\theta_{L}\right)=c, a_{R}(c)=n\right)\right]$ exists if the following 
condition holds

$$
(k+1) \theta_{L}-\Phi \leq \underline{U}_{S} \leq(k+1) \theta_{H}-\Phi .
$$

Given that the cost of the marriage proposal is higher for a type- $\theta_{L}$ than for a type$\theta_{H}$ Sam, the interval $\left[(k+1) \theta_{L}-\Phi ;(k+1) \theta_{H}-\Phi\right]$ is not empty and the separating equilibrium we are studying is feasible.

Our assumptions then imply that Robin's choices are optimal for her updated beliefs, $\tilde{\lambda}(m)=1$ and $\tilde{\lambda}(c)=0$, and given Sam's strategies. Specifically, when $a_{S}=c$ Robin's optimal choice is to break the relationship because, $U_{R}=\tilde{\lambda}(c) \theta_{H}+(1-\tilde{\lambda}(c)) \theta_{L}=$ $\theta_{L}<\underline{U}_{R}$; see Condition (2). When instead $a_{S}=m$, Robin's optimal choice is to accept the proposal if $U_{R}=\tilde{\lambda}(m) \theta_{H}+(1-\tilde{\lambda}(m)) \theta_{L}=\theta_{H}>\underline{U}_{R}$, which follows again from Condition (2).

Out-of-equilibrium beliefs that sustain this separating equilibrium are, for instance, given by $\tilde{\lambda}\left(a_{S}\right)=0 \forall a_{S} \neq m$

What happens when (3) is not satisfied? Suppose first that $\underline{U}_{S}<(k+1) \theta_{L}-\Phi$ so that $\left(I C_{L}\right)$ is violated. In this case it would be optimal for Sam to propose marriage irrespective of his type. But Sam's action then transmits no information and Robin would break the relationship because she cannot be sure about Sam's love $\left(E\left[\theta_{S}\right]<\underline{U}_{R}\right)$. Hence, Sam does not make a costly marriage proposal in the first place but suggests cohabitation $a_{S}=c \forall \theta_{S}$, which is refused by Sam.

Finally, suppose that $\left(I C_{H}\right)$ is not satisfied because $(k+1) \theta_{H}-\Phi<\underline{U}_{S}$. Then, Sam's optimal strategy is $a_{S}=c, \forall \theta_{S}$. Once again, Sam's action does not provide any information about his type and Robin prefers to break the relationship. To sum up, when the incentive constraint of either of Sam's types is violated there is a pooling equilibrium described by $\left[a_{S}\left(\theta_{H}\right)=a_{S}\left(\theta_{L}\right)=c ; a_{R}(c)=n\right]$. The following proposition summarizes results obtained so far.

Proposition 1 (Signaling without bonus/penalty) Suppose that $k \theta_{H}>k \theta_{L} \geq$ $\underline{U}_{S}:$

(i) Separation with marriage. If (3) is satisfied, then the separating equilibrium $\left[\left(a_{S}\left(\theta_{H}\right)=m, a_{R}(m)=y\right) ;\left(a_{S}\left(\theta_{L}\right)=c, a_{R}(c)=n\right)\right]$ exists with posterior 
beliefs $\tilde{\lambda}(m)=1$ and $\tilde{\lambda}(c)=0$ (and possible out-of-equilibrium beliefs as $\tilde{\lambda}\left(a_{S}\right)$ $\left.=0 \forall a_{S} \neq m\right)$. In words: Sam asks Robin for marriage when strongly in love and proposes cohabitation when weakly in love. Robin infers Sam's type from his action and thus accepts the marriage proposal while refusing cohabitation.

(ii) Pooling with no marriage. If (3) does not hold, then only a pooling equilibrium of the type $\left[a_{S}\left(\theta_{H}\right)=a_{S}\left(\theta_{L}\right)=c ; a_{R}(c)=n\right]$ exists, where posterior beliefs are $\tilde{\lambda}(c)=\lambda$ (and possible out-of-equilibrium beliefs are $\tilde{\lambda}\left(a_{S}\right)=0 \forall a_{S} \neq c$ ) In words: Sam proposes cohabitation irrespective of his type. No information transmission occurs and Robin refuses cohabitation so that the couple always breaks.

When (3) is satisfied, signaling allows information disclosure so that partners whose utility from living together is high are able to benefit from their good prospects. Potential partners who are weakly in love optimally opt for the outside-option and their relationship breaks. In this case, the signaling mechanism is beneficial from a welfare perspective because it allows the potential partners to overcome the problem of asymmetric information so that the "efficient" marriages are made possible. However, the information transmission comes at a cost, which the deeply in love Sam has to pay to signal his love and separate from the weakly in love Sam. From a welfare perspective this cost represents a waste as Robin draws no direct utility from Sam's signaling expenditure. Still, the signaling and the associated information transmission brings about a welfare gain. ${ }^{9}$ In next section we show how a marriage subsidy affects this (virtuous) signaling mechanism.

Equilibria with cohabitation only emerge when Sam's and Robin's preferences are fully aligned implying that Sam does not need to pay any cost in order to credibly transmit information. To illustrate this, consider the case where $k \theta_{H}>\underline{U}_{S} \geq k \theta_{L}$, meaning that both Sam and Robin would like to stay together only if Sam is deeply in love. A separating equilibrium with cohabitation emerges such that $\left[\left(a_{S}\left(\theta_{H}\right)=c\right.\right.$, $\left.\left.a_{R}(c)=y\right) ;\left(a_{S}\left(\theta_{L}\right)=0, a_{R}(0)=n\right)\right]$ and with posterior beliefs $\tilde{\lambda}(c)=1$ (and out-

\footnotetext{
${ }^{9}$ Obviously, less costly and thus more efficient signaling mechanisms might be feasible. As an example, in the Appendix we present a slightly different specification of our model that may generate a more efficient signaling mechanism because only a fraction of deeply-in-love Sam pay the cost of signaling.
} 
of-equilibrium beliefs $\left.\tilde{\lambda}\left(a_{S}\right)=0 \forall a_{S} \neq c\right)$. In words, Sam asks Robin to live together when strongly in love and breaks the relationship when weakly in love. Robin infers Sam's type from his action and thus accepts cohabitation when asked for. In this case marriage never occurs in equilibrium.

\section{Marriage or cohabitation under a marriage bonus}

Suppose now that the tax regime of couples translates into a bonus $B>0$ for married couples. Assume that $B$ is equally shared between the two partners so that it reduces the cost of the marriage proposal to $\varphi_{S}^{B}(m)=\Phi-\theta_{S}-B / 2$. Robin's utility in case of marriage becomes

$$
U_{R}=\tilde{\lambda}\left(a_{S}\right) \theta_{H}+\left(1-\tilde{\lambda}\left(a_{S}\right)\right) \theta_{L}+B / 2
$$

and Sam's incentive constraints are now given by

$$
(k+1) \theta_{H}-\Phi+\frac{B}{2} \geq \underline{U}_{S},
$$

and

$$
\underline{U}_{S} \geq(k+1) \theta_{L}-\Phi+\frac{B}{2} .
$$

Hence, a marriage bonus relaxes $\left(I C_{H}^{B}\right)$ but reinforces $\left(I C_{L}^{B}\right)$. This does not come as a surprise. The bonus will make a proposal more attractive for the high-type Sam; this is a "good thing" and makes the existence of a separating equilibrium more likely. However, the bonus will also make a proposal more attractive for the low-type Sam which is a "bad thing" from our perspective.

The condition for separation on Sam's side is now

$$
(k+1) \theta_{L}-\Phi+\frac{B}{2} \leq \underline{U}_{S} \leq(k+1) \theta_{H}-\Phi+\frac{B}{2} .
$$

This expression shows that the introduction of a marriage bonus shifts the interval of values for $\underline{U}_{S}$ for which Sam can credibly signal his type to the right.

In addition, the introduction of the bonus $B$ may affect Robin's best reply. Specifically, when no information is transmitted, or when she knows for sure that Sam's type 
is $\theta_{L}$, she will continue to refuse marriage or cohabitation only as long as

$$
\begin{aligned}
E\left[\theta_{S}\right]+\frac{B}{2} & =\lambda \theta_{H}+(1-\lambda) \theta_{L}+\frac{B}{2}<\underline{U}_{R}, \\
\theta_{L}+\frac{B}{2} & <\underline{U}_{R}<\theta_{H}+\frac{B}{2} .
\end{aligned}
$$

When $B=0$ these conditions are satisfied from assumption (1)-(2) but they may be violated when $B$ is sufficiently large. Observe that (5) implies $\theta_{L}+B / 2<\underline{U}_{R}$ and that $\underline{U}_{R}<\theta_{H}+B / 2$ follows from (2) as long as $B>0$. Consequently, Condition (5) implies Condition (6), but the opposite is not true. In words, (5) requires that Robin continues to refuse Sam's proposal to live together if she knew that his feelings are weak, which is a requirement for the separating equilibrium.

Comparing (3) and (4) and using (5)-(6) establishes the following proposition.

Proposition 2 (Signaling with a marriage bonus $B>0$ ) Suppose that $k \theta_{H}>k \theta_{L} \geq$ $\underline{U}_{S}$, and that (4) holds for $B=0$ :

(i) Signaling continues to be possible. If $B / 2 \leq \min \left\{\underline{U}_{S}-(k+1) \theta_{L}+\Phi ; \underline{U}_{R}-\theta_{L}\right\}$ conditions (4) and (6) are satisfied the separating equilibrium $\left[\left(a_{S}\left(\theta_{H}\right)=m\right.\right.$, $\left.\left.a_{R}(m)=y\right) ;\left(a_{S}\left(\theta_{L}\right)=c, a_{R}(c)=n\right)\right]$ continues to exist with posterior beliefs $\tilde{\lambda}(m)=1$ and $\tilde{\lambda}(c)=0$ (and possible out-of-equilibrium beliefs as $\tilde{\lambda}\left(a_{S}\right)=0$ $\left.\forall a_{S} \neq m\right)$.

(ii) Signaling is destroyed. If $B / 2>\underline{U}_{S}-(k+1) \theta_{L}+\Phi$, the incentive constraint of a weakly in love Sam is no longer satisfied so that (4) does not hold and signaling becomes impossible. Only pooling equilibria survive; specifically, we have:

1. Marriage crowding-out. If $\underline{U}_{S}-(k+1) \theta_{L}+\Phi<B / 2<\underline{U}_{R}-E\left[\theta_{S}\right]$, then only a pooling equilibrium with $\left[a_{S}=c \forall \theta_{S}, a_{R}(c)=n\right]$ exists, where posterior beliefs are $\tilde{\lambda}(c)=\lambda$ (and possible out-of-equilibrium beliefs are $\tilde{\lambda}\left(a_{S}\right)=$ $\left.0 \forall a_{S} \neq c\right)$. Sam proposes cohabitation irrespective of his feelings and Robin optimally refuses cohabitation so that the couple always breaks.

2. Marriage crowding-in. If $B / 2>\max \left\{\underline{U}_{S}-(k+1) \theta_{L}+\Phi ; \underline{U}_{R}-E\left[\theta_{S}\right]\right\}$, then only a pooling equilibrium with $\left[a_{S}=m \forall \theta_{S}, a_{R}(m)=y\right]$ exists, where 
posterior beliefs are $\tilde{\lambda}(m)=\lambda$ (and possible out-of-equilibrium beliefs are $\left.\tilde{\lambda}\left(a_{S}\right)=0 \forall a_{S} \neq m\right)$. In words: Sam proposes marriage irrespective of his type, and Robin accepts marriage so that all partners get married.

The previous proposition considers the case described in Proposition 1, (i) where a separating equilibrium exists when $B=0$. Not surprisingly, when $B$ is sufficiently small, the equilibrium is not affected. More surprising results obtain for larger levels of $B$, as soon as the incentive constraint of the low-type Sam is violated. Recall that this constraint is reinforced by the marriage bonus. The bonus then completely destroys the possibility of signaling (point (ii)). This implies that the marriage subsidy deeply interferes with the virtuous mechanism according to which a (market) failure induced by asymmetric information is mitigated thanks to the action (the marriage proposal) undertaken by partners who are really in love. In this case, only pooling equilibria exist and there are two possible outcomes.

In case (1) we have a pooling equilibrium with marriage crowding-out which is equivalent to the one described in point (ii) of Proposition 1. This occurs when $B$ is sufficiently large to make a proposal attractive to the low-type Sam but not large enough for Robin to accept the proposal, without information transmission (so that Condition (5) holds). ${ }^{10}$ Hence, Sam does not pay the cost of the marriage proposal and only proposes cohabitation which Robin refuses. While one might expect that a marriage bonus favors marriages, we obtain exactly the opposite result in this case. To sum up, the marriage bonus may effectively result in fewer marriages.

The second case occurs when the marriage bonus implies that (5) no longer holds and a new type of pooling equilibrium with marriage crowding-in emerges (case (2) of Proposition 2). Sam's optimal strategy is again $a_{S}=m \forall \theta_{S}$. But now Robin accepts the marriage proposal because remaining with Sam is better than the outside option, even when no information is transmitted. In this pooling equilibrium all partners stay together and marry even when Sam's feelings for Robin are weak.

In all situations described in point (ii) of the proposition, the marriage bonus de-

\footnotetext{
${ }^{10}$ This is of course only possible when $\underline{U}_{S}-(k+1) \theta_{L}+\Phi<\underline{U}_{R}-E\left[\theta_{S}\right]$.
} 
stroys signaling and thus reduces welfare in that either efficient marriages are not concluded (case 1) or inefficient marriages are induced (case 2).

Observe that to assess the impact of $B$ on welfare one has to account for the fact that the bonus must somehow be financed. To measure welfare with a $B$ different from zero we thus use the total surplus generated by the concluded marriages (including that due to $B$ ) minus the total cost of financing the bonus. This is equivalent to evaluating total surplus generated by marriages without counting the $B$ 's in individual utilities.

This proposition provides a rather negative view of the marriage bonus. That a marriage bonus distorts the decision to get married is not surprising in itself; see the Kaplow quote in the Introduction. From that perspective two main lessons emerge from our proposition. First, unlike traditional distortions in taxation theory, the marriage distortion is not continuous in $B$; once the critical threshold $\left(B / 2=\underline{U}_{S}-(k+1) \theta_{L}+\Phi\right)$ is reached, we have a discrete switch involving a drastic change in regime and a complete destruction of information transmission. ${ }^{11}$ Second, the sign of the distortion may be at odds with intuition because the bonus may effectively lead to fewer marriages.

Recall that Proposition 2 assumes that condition (4) is satisfied when $B=0$. When this is not true, a number of mostly trivial cases can arise. One interesting result emerges, though. Assume that $\left(I C_{H}^{B}\right)$ is violated for $B=0$. Then, a suitably designed marriage bonus may have a positive impact and make signaling possible. Recall, that the interval of $\underline{U}_{S}$ for which condition (4) holds depends on $B$. For any given $\underline{U}_{S}$ one can thus find levels of $B$ for which (4) is satisfied. If this can be done without violating (6) then the bonus induces a separating equilibrium and thus enables information transmission.

Now the sign of the distortion is as expected (a bonus produces more marriages), and the marriage bonus impacts on the marriage decision in such a way that welfare increases. Specifically, by making signaling possible it induces efficient marriages.

\footnotetext{
${ }^{11}$ Some smoothness may, however, be reestablished at an aggregate level when potential couples are heterogenous and the parameters, and particularly $\underline{U}_{S}$, are suitably distributed.
} 


\section{Marriage or cohabitation under a marriage penalty}

The previous section has considered the introduction of a marriage bonus and has shown that it may produce some unexpected results. In particular, it may prevent some marriages from being concluded. We now examine the case where the income taxation implies a marriage penalty so that $B<0$. We study the two cases separately because it turns out the they are not exactly symmetrical. A marriage penalty will reinforce the incentive constraint of the high-type Sam but relax that of the low type. It won't affect the decision of Robin if she is uninformed, or believes for sure that Sam is of the low type; in either case she'll continue to refuse the proposal. However, the penalty may also make a proposal unattractive which she firmly believes emanates from a Sam who is strongly in love.

Once again we start with a situation where $B=0$ so that the equilibrium entails separation with marriage. This yields the following counterpart to Proposition 2.

Proposition 3 (Signaling with a marriage penalty $B<0$ ) Suppose that $k \theta_{H}>$ $k \theta_{L} \geq \underline{U}_{S}$, and that (3) holds for $B=0$.

(i) Signaling continues to be possible. If $B / 2 \geq \underline{U}_{S}-(k+1) \theta_{H}+\Phi$ (so that (4) is still satisfied) and if $\underline{U}_{R}<\theta_{H}+B / 2$ (so that Robin accepts a marriage proposal from a deeply in love Sam despite the penalty), there is a separating equilibrium given by $\left[\left(a_{S}\left(\theta_{H}\right)=m, a_{R}(m)=y\right) ;\left(a_{S}\left(\theta_{L}\right)=c, a_{R}(c)=n\right)\right]$ with posterior beliefs $\tilde{\lambda}(m)=1$ and $\tilde{\lambda}(c)=0$ (and possible out-of-equilibrium beliefs $\tilde{\lambda}\left(a_{S}\right)=0$ $\left.\forall a_{S} \neq m\right)$.

(ii) Signaling is destroyed and marriage is crowded out. If $B / 2<\max \left\{\underline{U}_{S}-\right.$ $\left.(k+1) \theta_{L}+\bar{c} ; \underline{U}_{R}-\theta_{H}\right\}$ so that either (4) or the second inequality in (6) is violated, signaling becomes impossible and only the pooling equilibrium $\left[a_{S}=c \forall \theta_{S}, a_{R}(c)=\right.$ $n$ ] exists where posterior beliefs are $\tilde{\lambda}(c)=\lambda$ (and possible out-of-equilibrium beliefs are $\left.\tilde{\lambda}=0 \forall a_{S} \neq c\right)$. Sam proposes cohabitation irrespective of his feelings and Robin refuses cohabitation so that the couple always breaks. 
While Proposition 2 described the surprising property that a marriage bonus may actually prevent some marriages from being concluded, Proposition 3 does not show a similarly surprising result that a penalty may actually create marriages. But since the considered reference point is a situation where signaling is possible, it is clear from the outset that a penalty can only reduce the number of marriages.

However, a penalty can also produce less expected results if we consider a different reference point. This is illustrated by the following proposition.

Proposition 4 (Marriage penalty encourages marriage) Suppose that $k \theta_{H}>k \theta_{L} \geq$ $\underline{U}_{S}$, and that condition $\left(I C_{L}^{B}\right)$ does not hold for $B=0$ so that signaling is impossible in the laissez-faire.

If $\underline{U}_{R}-\theta_{H}<B / 2<\underline{U}_{S}-(k+1) \theta_{L}+\Phi$, the separating equilibrium $\left[\left(a_{S}\left(\theta_{H}\right)=m\right.\right.$, $\left.\left.a_{R}(m)=y\right) ;\left(a_{S}\left(\theta_{L}\right)=c, a_{R}(c)=n\right)\right]$ exists with posterior beliefs $\tilde{\lambda}(m)=1$ and $\tilde{\lambda}(c)$ $=0$ (and possible out-of-equilibrium beliefs $\tilde{\lambda}\left(a_{S}\right)=0 \forall a_{S} \neq m$ ).

Intuitively, this proposition starts from a level of $\underline{U}_{S}$ for which $\left(I C_{L}^{B}\right)$, the incentive constraint of the low-type Sam, is not satisfied. Consequently, both types want to propose and signaling is impossible. Now, a marriage penalty may lead to an outcome where a proposal is no longer attractive for a type- $\theta_{L}$ Sam (when $B / 2<\underline{U}_{S}-(k+1) \theta_{L}+$ $\Phi)$, while remaining the best strategy for type- $\theta_{H}$ Sam, and where Robin continues to accept a proposal from a deeply in love Sam despite the penalty $\left(B / 2>\underline{U}_{R}-\theta_{H}\right)$. In this situation, the penalty leads to a separating equilibrium with efficiency enhancing information transmission, which was otherwise not possible.

\section{Conclusion}

This paper has studied the impact of a marriage bonus or penalty on the decision to get married. We have considered a model where two potential spouses play a marriage proposal game at the end of which they may get married, live together without formal marriage, or split up. There is asymmetric information between the partners and we have concentrated on the case where absent of a credible transmission of information the 
couple would split. In this signaling game, proposing (or getting married) is costly but can indicate strong love (a high quality match). The striking property we obtain is that within this setting a marriage bonus may actually reduce the probability that a couple gets married. If the bonus is sufficiently large, the signaling mechanism breaks down, and only a pooling equilibrium in which fewer potential couples get married remains. In this case, the partners, whose union would otherwise be efficient, split. Similarly, a marriage penalty may increase the marriage probability. Specifically, the penalty may lead to a separating equilibrium with efficiency enhancing information transmission, which would otherwise not be possible. Our results also imply that marriage decisions in the laissez-faire are not necessarily privately optimal. In some cases a bonus or a penalty may effectively make the marriage decision more efficient; it may increase the number of efficient marriages that otherwise may not be concluded. However, when the signaling mechanism is operative, unless too small to have an impact, both bonuses or penalties will make the marriage decision less efficient.

Throughout the paper we have concentrated on a single couple identified by given parameter values. In reality, these parameters are likely to differ across couples. While any conjecture about their distribution would be highly speculative, one can expect that the different cases we have considered (as well as the "trivial" cases we have neglected) coexist in reality. Consequently, positive and negative effects of the bonus or penalty may at least in part cancel out through aggregation. This can explain that the empirical studies mentioned in the Introduction typically find that the tax regime applied to married couples appears to have little impact on the decision to get married. ${ }^{12}$ But even when the effect on the total number of marriages is small, this does not necessarily mean that the welfare impact of the tax regime is also small.

Turning to policy design, to the extent that the tax system potentially "distorts"a privately optimal marriage decision, one might think that this is an argument to move

\footnotetext{
${ }^{12}$ Chade and Ventura (2002; 2005) offer an alternative and complementary explanation and even document this result through calibration. They explicitly model the search process so that reservation levels are endogenous, but once the potential partners have met, they perfectly observe each others characteristics. We remain agnostic about the search process and consider the outside option as given, but instead focus on asymmetries of information between the potential partners. Interestingly, the two approaches yield similar predictions.
} 
to a more individual based tax. This would mitigate the marriage distortion, which for the rest has to be balanced against the redistributive benefits of a non-individual tax. This argument certainly applies when potential couples have full information so that marriage decisions are (hopefully) privately optimal. ${ }^{13}$ In our incomplete information setting it continues to go through for the couples where, for instance, the signaling mechanism is destroyed by a bonus, or where efficient marriages are crowded out by a penalty. However, our results show that for other couples it may play in the opposite direction. So overall, the way the optimal tax system is affect by endogenous marriage decisions depends on the distribution of parameters in the population.

Our analysis has also ignored children. In other words, we consider fertility decisions as occurring "downstream", once our game has been played. This in itself is a reasonable assumption in that fertility choices only become relevant if the couple does not split and decides either to get married, or to live in a civil union. However, in reality the tax treatment of couples is often intertwined with that of children. Children typically entitle the couple to various tax breaks, but very often these differ between married and civil union couples. From the perspective of our model this may effectively change the levels of the marriage penalty or bonus, at least in the case where the potential partners anticipate their fertility decisions. However, for the rest, this does not change our analysis.

\section{Appendix}

\section{A Alternative interpretation: probability of costly divorce}

As an alternative interpretation, let $\theta_{S} \in\left\{\theta_{L}, \theta_{H}\right\}$ with $\theta_{H}>\theta_{L}>0$ denote the probability that the matching between the two partners is long lasting. This probability represents the quality of the matching and is observable to Sam only. The matching of a fraction $\lambda$ of the existing couples is high-quality $\left(\theta_{S}=\theta_{H}\right)$, the matching of the remaining partners is low-quality $\left(\theta_{S}=\theta_{L}\right)$. This quality determines the two partners' utility.

\footnotetext{
${ }^{13}$ At least from an ex ante perspective.
} 
Sam chooses the action $a_{S} \in\{0, c, m\}$, where the strategies have the same interpretation and economic consequences as in the main text. Assume that (1) and (2) continue to hold. In words, Robin prefers to look for a new partner when the initial uncertainty about the quality of the matching persists. And she wants to accept Sam's proposal if she knows for sure that the matching quality is high $\left(\theta_{S}=\theta_{H}\right)$, while she refuses if she realizes that the quality is low $\left(\theta_{S}=\theta_{L}\right)$.

This alternative interpretation of Sam's type entails a slightly different specification of the cost function in the case of marriage proposal. Specifically, the marriage proposal now costs $\varphi_{S}(m)=\left(1-\theta_{S}\right) D$, where $\left(1-\theta_{S}\right)$ is the probability that the matching ends and $D$ is the cost of divorce. The expected cost of the proposal is thus lower when the quality of the matching is high: $\varphi_{H}(m)<\varphi_{L}(m)$. Here, the marriage proposal generates a partial commitment to remain together: after marriage, the union can only be dissolved by paying the cost of divorce. With cohabitation instead the relationship can be broken without any cost.

Robin's strategy set and the timing of the game are the same as before, whereas the two partners' utilities now are given by

$$
\begin{aligned}
& U_{R}=(1-I) \underline{U}_{R}+I \theta_{S}, \\
& U_{S}=(1-I) \underline{U}_{S}+I\left[M-\varphi_{S}\left(a_{S}\right)\right] .
\end{aligned}
$$

The difference from the specification in the main text is that, when Robin and Sam remain together, Robin's utility is increasing in the matching's quality, whereas Sam always obtains the benefit $M$, irrespective of the matching quality. Our main results are obtained for the case where $M$ is large enough to ensure $M \geq \underline{U}_{S}$, meaning that Sam prefers to remain with Robin if the proposal cost $\varphi_{S}\left(a_{S}\right)$ is not too large.

If the marriage proposal is accepted, Sam's utility is:

$$
U_{S}=M-\left(1-\theta_{S}\right) D=M+\theta_{S} D-D
$$

which is isomorphic to the one we presented in the main text $\left(U_{S}=(k+1) \theta_{S}-\Phi\right)$ and implies that all our results continue to hold. ${ }^{14}$ However, here the signaling cost is

\footnotetext{
${ }^{14}$ To see that, let us define $M=\theta_{S} M^{\prime}$ so that $U_{S}=\theta_{S} M^{\prime}+\theta_{S} D-D=\theta_{S}\left(M^{\prime}+D\right)-D$. Now, by setting $k+1=M^{\prime}+D$ implying $k=M^{\prime}+D-1$, we return to the specification used in the main text.
} 
paid only with probability $\left(1-\theta_{S}\right)$ so that this signaling mechanism is Pareto superior to the one presented in the main text.

\section{References}

[1] Alm J., S. Dickert-Conlin and L.A. Whittington (1999), "The marriage penalty," The Journal of Economic Perspectives, 13 (3), 193-204.

[2] Apps P. and R. Rees (1999), "Individual vs. joint taxation in models with household production," Journal of Political Economy, 107, 393-403.

[3] Apps P. and R. Rees (2009), Public economics and the household, Cambridge University Press, Cambridge, UK.

[4] Bénabou R. and J. Tirole (2006), "Incentives and prosocial behavior," American Economic Review, 96 (5), 1652-78.

[5] Boskin, M.J. and E. Sheshinski (1983), "Optimal tax treatment of the family: married couples," Journal of Public Economics, 20, 281-297.

[6] Bronsert A.K., A. Glazer and K.A. Konrad (2016), "Old money, the nouveaux riches and Brunhilde's marriage strategy," Journal of Population Economics, 30 (1), 163-186.

[7] Chade H. and G. Ventura (2002), "Taxes and marriage: a two-sided search analysis," International Economic Review, 43 (3), 955-986.

[8] Chade H. and G. Ventura (2005), "Income taxation and marital decisions," Review of Economic Dynamics, 8, 565-599.

[9] Cremer H., J.M. Lozachmeur and P. Pestieau (2012), "Income taxation of couples and the tax unit choice", Journal of Population Economics, 25 (2), 763-778.

[10] Cremer, H., J.-M. Lozachmeur, D. Maldonado and K. Roeder (2016), "Household bargaining and the design of couples' income taxation," European Economic Review, 89, 454-470. 
[11] De Fraja G. (2009), "The origin of utility: sexual selection and conspicuous consumption," Journal of Economic Behavior 83 Organization, 72 (1), 51-69.

[12] Kaplow L. (2008), The theory of taxation and public economics, Princeton University Press, Princeton, NJ.

[13] Leturcq M. (2012), "Will you civil union me? Taxation and civil unions in France," Journal of Public Economics, 96, 541-552.

[14] OECD (2005), Taxing working families: a distributional analysis, OECD Tax Policy Studies No. 12.

[15] OECD (2017), Taxing wages 2017, OECD Publishing, Paris. 


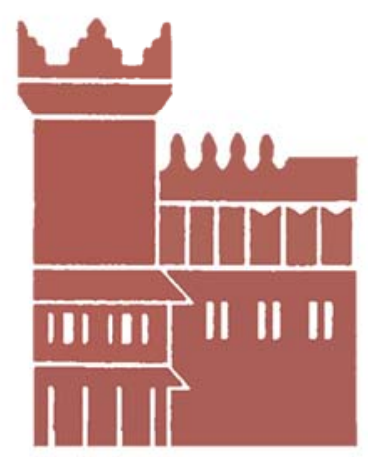

Alma Mater Studiorum - Università di Bologna DEPARTMENT OF ECONOMICS

Strada Maggiore 45

40125 Bologna - Italy

Tel. +39051 2092604

Fax +390512092664

http://www.dse.unibo.it 